\title{
Academic Advising Problems at Al-Quds University as Perceived by Students, and Its Relationship with Student's Academic Performance
}

\author{
Bassam Yousef Ibrahim Banat \\ PhD Sociology (Statistical Methods and Research Techniques), Assistant Professor, Department of Applied Sociology, \\ Faculty of Arts, Al-Quds University, Main Campus, Jerusalem- Abu Dies, Palestine \\ Email: bassambanat@yahoo.com, bbanat@arts.alquds.edu
}

\author{
Doi:10.5901/ajis.2015.v4n1p97
}

\begin{abstract}
This current study explores the main academic advising problems at Al-Quds University as perceived by students and its impact on their academic performance. It utilizes the sampling survey design. Three hundred and sixty-nine (173 males, 196 females) full-time undergraduate students at Al-Quds University were stratifiedly selected. Academic advising problems were measured using a 45-item questionnaire, and the grade point average (GPA) score was used to measure academic performance. Data were statistically analyzed using the Statistical Package for Social Sciences (SPSS) software. This study revealed that (74.8\%) percent of the students was reported to have experienced academic advising problems. The results demonstrated statistically significant differences in academic advising problems scores among the students according to their gender. Nevertheless, academic advising has emerged as a significant predictor of academic achievement.
\end{abstract}

Keywords: Academic advising, students, Al-Quds University, advisor, academic performance.

\section{Introduction}

In various academic stages and impacts it has left on student's personality, academic advising have received a lot of attention among researchers. However, this is evidenced by the numerous studies published by researchers. This trend came in response to the tremendous advancement in education whereby goals set forward often takes time, space, high ambitions, and cultural variation into considerations.

Historically, the term academic advising denotes different uses in educational literatures. "The notion of academic advising became prominent through Charles Eliot, who is the historic godfather of academic advising and the president of Harvard University. In 1870, he was appointed the first officer for disciplining and developing students. He was a pioneer in the application of elective courses, thus making it essential to give students advice and counseling in the courses they would like to select and enroll" (Rudolph, 1962; Veysey, 1965). In 1876, Johns Hopkins University established the system of academic advisors. During the thirties, most colleges and universities had established their own academic advising system (Grites, 1979; Bishop, 1987)

In spite of the increase in the numbers of students enrolled at universities after the Second World War, academic advising still receives little attention since it is considered as one of the basic duties of teachers. As scholars became more interested in research, student's body became more diverse. However due to the admission of the largest possible intake of students, the need for professional advisors and experts as well as comprehensive advising programs increased dramatically (Frost, 1991).

As stated by Tuttle (2000), Crookston (1972) in the article titled "Developmental Advising", and O'Banion, (1972) articles on the model of academic advising which consist of five different stages; a turning point in the nature of academic advising in higher education in the United States of America was created. Furthermore, doors have been opened wide to seek specialization and professionalism in this regard. The first national conference on advising in the USA was held in 1977; and the National Association on Advising was established in 1979. The National Association on Advising published its first refereed journal in 1981 (Beatty, 1991). Consequently, the high rate of university dropouts in academic advisory, the lack of interest on the part of the faculty, and students' demands for an improved process of advising have led many universities and colleges to set up their own academic advising centers. These institutions have also exerted more effort in increasing the so called "coordinated advising" especially during the seventies and eighties. These centers focused on academic advising as a symmetrical and parallel developmental process with the educational and teaching process. Thus, it is not only limited to office work such as registration and review of graduation requirements, but requires that it is 
essential to focus on the student as the core of the advising process in order to help students to take responsibility for their decisions to study the advising process (Winston et al., 1984; Habley, 1988; Frost, 1991).

Furthermore, research results has pointed out that academic advising, influence and increases students' motivation and interest in studying (Chickering \& Gamson, 1987; Frost, 1991). By the same token, Oliver (1978: 18-22) states that the need for academic advising had existed a very long time ago. However, it resurfaced at a larger and deeper level ever since the development of the system of credit hours in both Arab and foreign universities and colleges around the world.

However, in Arab universities, academic advising interest has increased due to the development of the higher educational system besides the application of the credit hour system. Since the higher education system is different from lower education systems, students' coexistence with the university's system has caused them several problems in relation to adaptation. A system which students did not know about throughout their general education is the credit hour system which gives students the freedom to select courses of their choice. In this regard, Atiyat \& Mufti (1986) indicates that the transfer of a student from the secondary stage to the university stage creates new conditions that the student has to adapt to; otherwise, the student will face some maladjustment problems.

The credit hour system was launched in the Arab world in the early seventies. Thus, the University of Jordan was the first to replace its annual teaching system with this new system (Oliver, 1978). Al-Quds University since its establishment in 1978 has adopted the credit hour system like other universities in the occupied territories. Ahmed (2002) points out that the success of the credit hour system depends on the availability of several factors as well as the availability of academic, technical, and financial potentials. Therefore, the most important of all is academic advising process of students which is the backbone of the credit hour system.

\section{Background and Literature Review}

Academic advising is defined as, " a process which aims to help students discover their capabilities and potentials in order to help them make decisions related to their study program, selection of major study courses, and to assist them in overcoming difficulties which might obstruct the students' academic or study progress" (Sayyid Ahmed and Rawi, 1995). Accordingly, students benefit particularly from the applied advising system in the university through the following ways:

1. Identification of university's requirements, faculty's requirements, major requirements, and paradigms and study programs offered by the Faculty in addition to the stipulations and prerequisites of each program.

2. Identification of the level of academic progress and performance, and the way to match the student's actual capabilities with the level of his academic ambitions.

3. Identification of students' own capabilities, aptitudes and academic level based on tests given to them in order to advise and direct them accordingly.

4. Helping students to determine the programs or specializations that best suit their aptitudes, capabilities, potentials, and interests.

5. Helping students to solve any academic problems or obstacles they are facing, and suggest most appropriate solutions to prevent them from any failure or dismissal from university.

6. Improving students' study skills like the use of library, note taking, report writing, and exam preparations.

7. Improving student's social skills like having friendly relationships with teachers, students, and taking part in different activities.

8. Coordinating with local community institutions whether on or off campus whenever the need to help students solve any of their academic or non academic problems arises.

Furthermore, Marques (2005: 4) found the top five best practices for an academic advisor that should be employed by every faculty's advisor to ensure that each student has the opportunity to attend college in a supportive environment that enhances learning and development. They are as follows:

1. Advisors should be knowledgeably involved with the student's position and program.

2. Advisors should be tuned to the student's personal well-being in the learning environment.

3. Advisors should be available to the students in several ways (in person and by telephone, e-mail, or fax).

4. Advisors should be honest with adult learners.

5. Advisors should develop and maintain a peer-to-peer relationship with the adult learner.

Consequently, as for the methods and regulations of academic advising, Sayyid Ahmed and Rawi (1995) indicate that there are a number of approaches applied by universities in offering academic advising services to students. Such academic advising services includes advising by faculty members in addition to their teaching duties, advising by 
specialized full-time specialists and not from the faculty, advising by post graduate students, instructors, teaching assistants in addition to other methods like self advising and computerized advising.

According to Pargett (2011: 11), there are two approaches to advising students: one is called "prescriptive", where the advisor tells the student what needs to be done in order to graduate; and the other is called "developmental", where the advisor and student collaborate together to ensure that the students graduates on time. A prescriptive advisor does not allow the student to make their own choices in the direction of their education, but rather the student receives instructions on what they should do according to their advisor. The relationship between a student and advisor who uses prescriptive advising is very impersonal and authority-based, answering only specific questions and not taking the development of the individual into consideration

Additionally, Abu Saymeh (1984) points out that the tasks of an academic advisor are as follows: fill out study plan, follow student's academic performance, help student to select courses, provide accurate information about teaching options and available services, and solve student's problems especially academic ones in addition to other tasks. In this context, Omari (1986) indicates that the process of academic advising is not limited to issuing higher educational directions and policies, but it is also an interactive relationship between the academic advisor and the student. The advisor introduces the student to the university life and available activities and experiences that are different from school life. The advisor also familiarizes students with the university's rules and regulations and study systems; provides facts about academic life as a specialist in the field, its prospects, applications in real life and available employment opportunities; and the advisor sets a model for students. Besides, he symbolizes seriousness, perseverance and success. As a result, the students learn good conduct from him, and acquire problem solving skills in a scientific and logical way.

Furthermore, Petress (2000) argued that it is essential to have a mutual academic advising process between the advisor and advisee in order to be a good advisee. It is represented in the need for interaction between the advisor and advisee, readiness and preparation for advising sessions, and the availability of right and accurate information. Besides, the study emphasizes that advising is not limited to specific periods of time, but it is an ongoing and continuous process by both sides. Hence, emphasis must be placed on the desire and ability to ask quality questions during an advising session. The researcher stressed that such approach would help to have an efficient academic advising, encourage students to progress academically, improve their psychological condition, and help them to put their logical and long term plans together. Thus, the scope of the problems the students' faces will be reduced.

\section{Further Related Studies}

Academic advising has been an aspect of debate in the field of higher education and social sciences. Several articles and studies which tackled academic advising as a multi-dimensional phenomenon addressed by both theoretical and applied researches were published. In a recent study, Allogmani (2014) revealed clearly that students experienced the following obstacles of academic advising: obstacles related to student himself, obstructions related to advisor professionally, impediments attributed to the availability of advisory services at certain time and place which is related to the program of advising and student services. The study of Adena et al. (2013) showed that six interpretable factors (i.e. advisor's accountability, advisor's empowerment, student's responsibility, student's self-efficacy, student's study skills, and perceived support) significantly related academic advising to the success of the students.

The study of Aldahadha \& Al-Bahrani (2012) concluded that academic advising services emerged as a significant predictor of academic achievement. Also, Pargett (2011) found a relationship between academic advising, student's development, and student satisfaction with college. On the contrary, no significant relationship was found between academic advising and academic performance in the study of Muola et al. (2011).

In an article titled, "Academic advising: who offers it? How does it work", Tuttle (2000) considers that these two questions have been the most frequent questions about academic advising over the last twenty years. Accordingly, educational institutions started to offer advising services based on a number of possible models, most important of which is the Faculty-only Model. Furthermore, it was the most common among all educational institutions; however, the use of this method started to drop and it is only applicable to $15 \%$ of universities awarding Bachelor degrees in the United States of America. However, the popularity of the Split Model has increased. It consists of an advising center for a number of students like those who do not have a declared major. As for the rest of the students, a very high percentage had advisors in academic departments. $27 \%$ of universities in the United States follow this system, and almost half of the universities which are offering a four-year study program also use this system along with $30 \%$ of Community Colleges. As for the third model which is the "Supplementary Model", students are assigned to a faculty member as their advisor. 
There is also an advising office which gives general assistance to students. This model is spread among private universities. As for the "Total Intake Model", employees render advising services to all students for a specific period of time. After then, the students will be transferred to their respective departments. However, this model creates an opportunity for having a large number of employees who are experts in advising, and it is well common in community colleges. Finally, there is an independent model called "Satellite Model" in which every academic department is responsible for its advisees. Thus, it gives an opportunity to have several positions on campus.

Moreover, Harithy (2000) stresses the need to activate the role of the academic advisor through a group of approaches and mechanisms in the form of a matrix through which the computer is used as an advisor or assistant to fulfill the role of an academic advisor with regard to selection of courses, study load, and prioritization of courses according to specialization and in harmony with the student's conditions. In addition, it can carry out a process of psychological, social and educational advising through what is known as Artificial Intelligence Programs.

In relation to organization and administration of academic advising, universities differs in their approach since this depends on a number of factors influencing the model of the adopted and applied organization. However, the majority of these systems may follow a centralized or a decentralized approach of management. Within this framework, a central advising system will supervise the advising process at the university level. It will include a number of academic advisors, while the approach of decentralization of advising depends on the availability of several bodies which will be in charge of advising. This can be seen as small administrative units attached to every faculty in the university. Undoubtedly, each system has its strong and weak points (Hammad, 2000).

Additionally, academic advising plays a fundamental role in the student's university life beginning from the moment he is admitted to the university until the time he has graduated. An academic advisor is considered a part of the total educational process in the university life. This advisor plays the role of the educator and his responsibility is to build a relationship of cooperation based on trust and honesty with the student. This would enable the student to decide what and how to be apply the information made available to him by the academic advisor (Hammad, 2000). In this context, Abdel Hadi and Azzeh (1999) focused on the significance of the advising relationship which is considered as a fundamental element in the process of advising. They base their view on (Roger, 1959) Humanitarian Theory which states that successful advising is the basis in bringing about a change in behavior. If the student feels secure and free from any threats, he will be able to go over his previous experiences and fully assimilate them with the help and support of the advisor. This true perception of experiences would release the motivating force of the student to fulfill the goals of academic advising. Advising alone is not enough to bring about the desired change. However, positive advising relationship is a prerequisite for academic advising. Meanwhile, Mohammed (1995) reinforced this view when he found out that one of the main reasons that obstructed academic advising and established distrust was the difficulty the student faced in dealing with the academic advisor who was unavailable. Hence, this made it difficult for the student to deal and understand him. This academic advisor was ignorant of the rules and regulations and did not have the enough time for academic advising.

In his article, "Visiting academic advisors continuously", Carlin (2000) highlights the significance of following up with your academic advisor in the process of student development over a period of four years. He indicated that the student must stay in contact with his academic advisor in order to benefit from the available academic services. Besides, Melvin (2000) stresses the significant relationship between the student and the academic advisor. The researcher refers to several academic problems and disturbing incidents happening to students as a result of this poor relationship. She stresses that it is essential for the student to keep in touch with the academic advisor until the advising process becomes a professional value. In this regards, the study of Muola et al. (2011) recommended that academic advising should actively involve more students.

Furthermore, Hunter et al., (2004) wonders that in the event of reformation, academic advising would be able to reform higher education? The author stresses the importance of effective academic advising in improving the quality of higher education. The article introduces fundamental elements for an effective and ideal advising system. If it is applied as expected, it would provide a better opportunity for advising between the students and the teaching staff. Also, it focuses on students who are the core of the academic institutions since the mission of academic advising is considered the vital foundation for the general and specific objectives of academic advising program. In the same time, Dibia \& Obi (2013) found that academic advising and counseling is the lynchpin for students' success in the university and is integral in fulfilling the teaching and learning mission of higher education. Consequently, most of the academic advisers were not always accessible and the institutional mechanisms were weak.

Academic advising plays an important role in the system of credit hours adopted by Al-Quds University. Ever since its establishment, the university was particularly keen in providing good academic advising to its students during the 
period they spend at the university. It also made a preliminary step by giving a preliminary advising and counseling sessions to Tawjihi (Secondary level) students. Then, it offers general advising to university freshmen followed by specialized advising to students upon specialization until graduation. It seeks to fulfill their psychological, social, and educational harmony with the new atmosphere of the university. The university believes in strengthening the relationship between students and faculty members. It adopts the Supplementary model and each student is assigned a faculty member in order to provide the students with good university expertise and to help them make the right decisions closely related to their academic journey. The university has introduced an electronic registration system in 2007/2008. In academic advising, the university focuses on the following aspects:

1. The process of general advising of university students seeks to stress the university goals, illustrate the admission system, and introduce university system and its different programs of study offered by different faculties, scientific departments and available specializations. It also aims to offer information to help students choose specializations that meet their capabilities, potentials, and interests. Fresh students are given special attention in this kind of advising. They are introduced to the university, its faculties, available specializations, credit hour system, and the elements of program of study with emphasis on the introduction of different courses. They are given assistance to understand and assimilate the university environment so as to overcome any study difficulties in future.

2. As for specialized advising of students, sophomores are subjected to specialized advising implemented by the department chairperson until the students have graduated. The chairperson is considered the main reference to all students whose major or minor is taught by this department. The chairperson will draw up a detailed paradigm (study plan) to each student. It includes all graduation requirements which are distributed on different semesters. In addition, the student is given a copy and the department faculty members advise those students.

3. The Department of Students' Affairs at Al-Quds University carries out activities that serve students especially graduates. It concentrates on teaching them how to write their curriculum vitas. It also holds a career day where graduates meet all representatives of institutions of the local community from all over Palestine. These institutions recruit a large number of those graduates. In spite of the university's focus on academic advising, some problems that face students in this regard have appeared. The researcher has noticed those problems in reality during his work at the university.

In addition, the process of academic advising is supposed to be an uninterrupted process beginning from the time the student is admitted, registered for courses and graduated from university. However, the student's need for academic advising increases at certain times like applying for study for the first time, at the beginning of courses registration, and in addition to drop period. In this context, Shbiyl (2004) points out that the absence of effective academic advising at the university might lead to great educational waste leading to the confusion of academic advisors in carrying out their responsibilities. Also, students may commit certain negative behaviors that are in breach of the university rules like: registration of course outside their paradigm, register courses without taking their prerequisites, delay in taking certain courses which future courses depend on, failure in certain courses, delay in withdrawal from certain courses which constitute a studying problem or increase in their study load. This would lead to a drop in their average grade point leading to a loss of money and effort, postponement of graduation, and the formation of negative attitudes on the part of the students regarding the system of credit hours and maybe the university. Besides, Rabai (1984) mentions that the reality of academic advising in Arab universities is still facing negligence and indifference in spite of labeling the advising process as one of the most important stages of university.

It is noticed through a review of previous literature on academic advising that the results of these studies showed that students in general face problems throughout their different educational stages including university students. These problems have increased during the eighties and nineties. Academic services are essential in the educational institution; however, they sometimes do not meet the advising needs of the students especially in the absence of a clear understanding of the concept of academic advising. This is reflected in the emergence of some problems facing students in their university life. They need advising services and psychological care. Such needs vary in accordance with the variables of gender, academic level, and faculty. There are some differences in the results between Arab and foreign studies. Regarding the need for academic advising, Abdel Munim (1996) points out that we are living at the age of variables and challenges, the age of contradictions, the age of cultural, social and educational changes, the age of competition and successive changes, and the age that is dominated by material things. However, this causes several university students to suffer from so many problems and disorders. This usually causes huge damage to their personal growth and academic progress due to their low potentials and capabilities compared to adults. If this is the situation in 
natural conditions in the lives of people, so what would the situation be generally in the lives of Palestinian university students, and students at Al-Quds University? These are facing the fiercest occupation ever known in human history. As we know, the need for counseling and advising services increases during times of crisis lived by societies. The Palestinian society which is under the yoke of occupation is suffering from economic, educational, social and political crises which are ongoing up till this present day. This need must be addressed by local community institutions in general, and the university where the students study in particular.

\section{Purpose and Scope}

The absence of an effective academic advising at the university leads to a waste of the educational process and leads students to commit certain negative behaviors that are in breach of the university's rules. This is due to the absence of a clear understanding of the philosophy of academic advising, its objectives, and concept or procedures by both students and academic advisors. These problems undoubtedly influence students' attitudes towards academic advising and academic performance. Here lies the study problem. Such considerations have made it essential to address the problems of academic advising at Al-Quds University as perceived by its students. The university has about (12,000 males and females) students studying different specializations at different study levels. These students face several problems in different areas as a result of the nature of university life on one hand and the public life on the other hand. When a student gets admission into university, he/she is in great need for somebody to advise him/her in order to overcome and adapt with these problems. NACADA's (2004) "Statement of core values in academic advising" suggested that the advising process should be shaped by understanding the needs of an institution and its students. The idea of the current study stems from questions that arose during the researcher's work as a chairman of the Department of Applied Sociology at Al-Quds University and prior to that as an academic advisor as well.

The primary goal of the current study, however, is to investigate the academic advising problems of Al-Quds University as perceived by students, and to check how academic advising predicts students' academic performance. In addition, group differences were examined to highlight factors which have contributed to academic advising problems.

The significance of this present study comes from the fact that it sheds light on the problems of academic advising at Al-Quds University as perceived by its students and its relationship with academic performance. The current study is considered one of the pioneer studies that deals with the research of this topic. It is expected that the study would add new scientific knowledge in this area. Its significance is also portrayed in presenting some recommendations and suggestions to the university administration in order to contribute to the success and development of the educational process at the university. Also, it assists students to pursue their university study and reduce the number of problems which might prevent them from pursuing their university education and sometimes deprive them of it. According to Kelley (2008), the assessment of academic advising is not as advanced as that of classroom learning. Historically, the measurement of advising outcomes was focused on student's satisfaction with the advisor or advising system rather than on student's success.

\section{Definition of Terms}

Advising: Advising is a process whereby advisor and advisee enter into a dynamic relationship with respect to the student's concerns. Ideally, the advisor serves as a teacher and guide in an interactive partnership aimed at enhancing the student's self-awareness and fulfillment (O'Banion, 1972).

Advisor: Advisor is a staff member who helps to ensure that students' individual academic plans are consistent with their academic interests and abilities. Furthermore, the advisor provides the students with current and accurate information regarding the curricular and academic policies, and serves as a referral agent. Academic advising is one of the only services that guarantees interaction with students, and offers a unique opportunity for faculty to develop positive and lasting relationships that can promote student's development (Midgen, 1989; Aldahadha \& Al-Bahrani, 2012).

Academic Achievement: The grade point average (GPA) score in the university was used to measure academic achievement. Participants were asked to self-report GPA in their 2013/2014 second semester.

\section{Limitations}

The population of this study was limited to undergraduate students of Al-Quds University, main campus, Jerusalem, Abu Dies, for the 2013/2014 academic year. 


\section{Hypotheses}

Taking into consideration the set objectives, the researcher developed two main hypotheses:

1. There are no statistical significant differences at $a \leq 0.05$ in the academic advising problems of Al-Quds University students based on gender, college, and academic year.

2. There are no statistical significant correlation at $a \leq 0.05$ between academic advising problems and academic achievement (GPA) of Al-Quds University students.

The independent variable academic advising problems were measured using a 45-item scale, in addition to the dependent self-reported variables which included: academic performance (GPA), gender, college, and academic year.

\section{Methodology}

This study is quantitative in nature using a questionnaire to assess the impact of academic advising problems on the academic achievement of Al-Quds University students.

\subsection{Sample}

The sample constitutes three hundred and sixty-nine students (173 males and 196 females) full-time undergraduate students at Al-Quds University stratifiedly selected based on gender and academic year. The sample size was calculated using the sampling web of http://www.surveysystem.com/sscalc.htm, sample size calculator with a margin error of 0.05 . The sample constituted (3.8\%) of the target population. The target population consists of Al-Quds university students in the main campus-Abu Dies in the academic year 2013/2014, which includes nine thousand four hundred and sixty-four students (4421 males to 5043 females) (Al-Quds University, 2014).

\subsection{Instrumentation}

The instrument was a self-administered questionnaire developed by the researcher. The sampling survey involved asking Al-Quds University students to answer a questionnaire which was administered using face to face interviews. The questionnaire consists of two main sections: the first has the background information of the students mainly as gender, college, academic year, and GPA, while the second measured academic advising problems using a 45-item questionnaire divided into three main groups: problems related to the university, advisors, and that related to the students themselves. In addition, the well known 5-point Likert Scale (Strongly agree, agree, neither, disagree, and strongly disagree) was used in the questionnaire to measure responses.

\subsection{Validity and Reliability}

Concerning validity and reliability, validation of the instrument proceeded in two distinct phases. The initial phase involved a small focus group session ( $\mathrm{N}=18$ ). The second phase involved the implementation of a pilot study $(\mathrm{N}=50)$ to validate the survey using exploratory factor analysis. Factor loading for all items exceeded 0.50 (0.53 to 0.81$)$, which means that those items are suitable in measuring every dimension of academic advising problems at Al-Quds university. This is in light of the theoretical framework that the scale of study is based upon. Moreover, Cronbach's Alpha and Guttman splithalf coefficients were incorporated to ascertain reliability and consistency of the survey. Cronbach's Alpha and Guttman split-half for the survey instrument was 0.93 and 0.87 , respectively. Hence, it indicates an excellent reliability and consistency.

\subsection{Participants}

Cotextual variables distribution includes gender, college type, and student average (GPA). A total of three hundred and sixty-nine participants completed the interviews. Males represented $46.9 \%$ of participants, while the remaining $53.1 \%$ were females. In terms of college, $42.4 \%$ of the sample was from arts compared to $57.6 \%$ from science colleges. As of academic year, $17.1 \%$ of participants were from the first academic year, $27.4 \%$ were from the second academic year, $21.7 \%$ were from the third academic year, while $33.9 \%$ of them were from the forth academic year and above. Respondents was between 60 and 94 score of GPA, with an average age of 75.5 points. 


\section{Data Analysis and Findings}

Data analyses were undertaken using statistical Package for Social Sciences (SPSS) version 20. The questionnaire items were ranked according to a 1-5 Likert scale (strongly agree, agree, neither, disagree and strongly disagree). These rankings were codified into a quantitative score from 1 to 5 , with higher aggregated scores indicating stronger academic advising problems. Descriptive statistics were generated to gauge the rate of academic advising problems among the sampled student population. Additionally, the following statistical techniques were measured: Pearson Correlation, T.test, One way analysis of variance, Cronbach Alpha and Factor Analysis.

The results of this study show that the mean academic advising problems score for the 369 participants of Al-Quds University students was high (M 3.74 SD 0.59 ). The total score showed that $(74.8 \%)$ of the students experienced academic advising problems related to the university and advisory services mostly (M 3.97 SD 0.55), then to the advisors proficiency (M 3.68 SD 0.84), and finally to the students themselves (M 3.57 SD 0.60).

Moreover, findings revealed the main problems of academic advising related to the university and advisory services ranked in a descending order as follows: the small number of sections of courses provided (M 4.20 SD 0.92), and there is chaos at the university academic advising operation (M 4.11 SD 1.03). Also, students indicated that the accurate academic advising at the university is absent (M 4.10 SD 0.99), in addition to changing courses duration during registration period (M 4.09 SD 1.05), and there is no way to help students in order to treat postponed financial problems (M 4.07 SD 0.90). In general, students emphasized that the registration regulation is difficult in the university (M 4.06 SD 1.03). As for academic advising problems related to the advisors proficiency, they were as follows: lack of collective advising meetings held by the academic advisor (M 3.84 SD 1.20), the large student number assigned to the academic advisor (M 3.81 SD 1.08), academic advisors disability to advice students as it is lacking (M 3.60 SD 1.20). Also, the students emphasized that the communication difficulty is found in connecting with the academic advisor (M 3.58 SD 1.15), since they are feeling of a distance between them and their academic advisors (M 3.56 SD 1.25). Besides, nearly half of the students (42.3\%) indicated that they want to change their current academic advisor. In terms of academic advising problems related to the students themselves, mainly were: lack of students' ability to pay fees during registration period (M 4.08 SD 1.06), ambiguity of the academic advising concept in university students minds (M 3.71 SD 1.06), and students are not convinced of academic advising operation (M 3.67 SD 1.03). Also, students do not follow advertisements on registration event (M 3.66 SD 0.99) since they mistrust academic advisor (M 3.65 SD 1.39).

Additionally, the study investigated demography over academic advising problems based on locational differences with the aim of identifying any differences. Findings show that college and academic year do not indicate any significant difference. However, it was found that gender is significant in academic advising problems. Therefore, the differences is in favor of males (M 3.71 SD 0.52) compared to females (M 3.57 SD 0.64) as T.test value was (2.213 P=0.028).

Furthermore, findings indicated that there are statistical significant negative correlation between academic advising problems scores of Al-Quds University students and their academic performance. It was found that academic advising problems were higher in students who had less academic performance and vice versa as R-coefficient was (-0.657 $\mathrm{P}=0.000)$.

\section{Discussion}

Findings of the current study indicated that the problems of academic advising at Al-Quds University are high. $74.8 \%$ of university students are suffering from various problems in academic advising. They share in the many problems of academic advising of other university students which mainly erupt because of the university, academic advisor, and students themselves. The researcher's view is that this outcome is expected in a university like Al-Quds University where there are so many social, cultural, educational, and psychological events and incidents. The university student faces several problems on all levels. The student moves from school to university, so he is in great need for somebody to advise him in order to overcome and adapt to these problems within the framework of his own capabilities and potentials.

Najim \& Rashad (1996) reinforce this position by stressing that the philosophy of academic advising is based on the development and growth of the student personality through identification of his aptitudes, inclinations, psychological and health condition, the extent of his cooperation and trust in his academic advisor in order to help him to face his personal and academic problems, make right decisions, determine his academic and career future on scientific basis that fulfill his ambition and help to develop his personality. The previous result indicates that the channels of communication between the student and his academic advisor are unsound and poor. The researcher relates the aforementioned to a number of issues. Most importantly, they are: students feel that their advisors are not well versed of the university rules 
and regulations; thus, they lose confidence in the prospect of benefiting from them and receiving directions from them. Students feel that advising is an electronic approval by the advisor of the student's schedule or they feel that their advisors lack the knowledge and information about their advisees. This can also be explained on the basis that some teaching faculty feels that advising is not part of their specialization and they look down on it. Thus, they would not perform their advising job as they are expected or because their advising session does not match or suit the student's time. Therefore, the student cannot benefit from the set time designated by the advisor. Also, Mohammed (1995) reinforces this view by stressing that the problems of academic advising are mainly due to ambiguity of the philosophy, goals and procedures of academic advising to both students and academic advisors. This is reflected on the students' attitudes towards academic advising and its significance to them.

The previous results put the problem of advising along with its forms and different models on the table for discussion and research by specialists at the university since the university student needs for advising is considered one of his basic needs. This indicates that students are in need for a large scale advising process whether on the individual or collective level in order to help the student overcome his problems, ease them, or adapt themselves to them.

Furthermore, results found that more male students are suffering from academic advising problems than females, taking into consideration the unavailability of male students on campus during the process of academic advising and registration. They do not regularly visit their advisors as females do. In fact, they are working during the university's official and unofficial holidays to be able to pay for their study tuition. We assume that females have fewer number of curriculum activities than males, and they are likely to adhere to the rules, directions, and advisor instructions. Also, most females live inside the university campus which gives them the chance to stay in touch with faculty members and advisors. Besides, males especially in an Arab Palestinian society which has conservative norms and traditions, male patriarchal dominance and social upbringing which is based on gender discrimination are less willing to seek help in dealing with academic advising problems. Students also indicated that there is a clear discrimination between males and females in academic advising as advisors are in favor of females at the expense of males. Thus, this is reflected in the increase of males suffering from problems of academic advising. Besides, significant results were found for gender on student's responsibility, as females' rates higher than males in taking responsibility for their academic success. Results suggested that females take more responsibility for their academic success throughout an academic semester (Adena et al., 2013).

The study results also revealed that college and academic year do not indicate any significant difference in academic advising problems. This indicates that the problems of academic advising at the university are not very much influenced by these variables. Despite the diversity of students, they all live in the same social, psychological and academic conditions and suffer from almost similar advising problems. Academic advising problems in university are more likely to be affected by other factors other than college and academic year.

Findings revealed a negative correlation between problems of academic advising and student's grade point average (GPA). The more the problems of academic advising increase, the lesser the student's academic performance becomes and vice versa. This indicates that academic advising is a good indicator of the level of student's performance. The problems of academic advising may overlap and influence the level of motivation and learning strategies, and eventually the academic progress of students at the university. The findings of this study are similar to some findings in the related studies and disagreed with others as well.

\section{Conclusion}

The concept of academic advising adopted by a university, the extent of awareness of academic advisors and stakeholders in the academic advising concepts, and the extent of clarity of the role of the academic advisor plays a big role in the success and benefit of this process. However, just as the inadequacy of this concept, its ambiguous form and nature along with the absence of a clear job description of the role of the advisor plays a big role in the failure in offering academic services and benefiting from them. Thus, the significance of academic advising lies in the fact that it is a basic cornerstone in the university; it is the connection point between student semester schedule and registration. The clearer and more specific and controlled the academic process is, the easier and simpler the registration process becomes. Advising is not only giving advice and preaches that can be given by anybody, but it is also a controlled, organized, and systematic process based on scientific and moral basis in providing academic advising assistance to those who needs it. In this context, Shikhly (1983) points out that the purpose of academic advising is not in reminding students about areas of failure, negligence and dereliction of students in their academic and educational path and overcoming problems they encounters, but it is also directing and guiding them in the manner that helps them to become an effective and a 
thinking force through raising discussion and debate with their colleagues and teachers alongside with thinking about the ways on how to solve their problems in scientific ways.

Conclusively, academic advising is an important aspect which has a significant impact on student's development in higher education. The findings of the study provide support that shows the importance and impact advising problems has on students in general, and their academic achievement in particular. Academic advising emerged as a significant predictor of academic achievement. A lot needs to be done in the area of academic advising in terms of student needs, expectations, and success rather than through the traditional lens of student satisfaction with the process. This can be done through an effective collaboration amongst the university, advisors, and students, which would lead them to a feeling of stability. Thus, it would positively motivate them to increase their academic achievement. In this regards, Pietras (2010) concluded that if institutions plan to continue advising programs, they should seek to substantiate its effectiveness. However, this might lead to restructuring the provision of advising services in an effective and efficient means that meets the needs of both the colleges and the students.

A discussion of the results of the study reveals the need of university students for assistance in overcoming their different problems especially those related to the preparation of the advising program, or recommendation to adjust rules and regulations to meet students' needs and that of the educational process.

\section{Recommendations}

In light of the results of this present study, the following recommendations are made:

1. Offer a compulsory course in academic advising to all university students.

2. Need to develop the electronic registration system enforced at the university.

3. Offer enough time for interaction and contact between the student and his academic advisor, and give advisors more authorities and flexibility in dealing with rules and regulations of both electronic and paper academic advising.

4. Concentrate on students as the core of the advising process, and encourage them to exercise more responsibility in the process of academic advising.

5. A need to establish an advanced psycho-educational advising center at the university and activate its activities to offer advising, developmental, and remedial services focusing on the development of the bright and optimist sides of university students' personalities.

6. Further research is essential to expand the understanding of academic advising and its measurable impact on the personal and institutional aspects of student success.

\section{References}

Abdel Hadi, J. \& Azzeh, S. (1999). Principles of guidance and counseling. Amman: Dar Al-Thaqafa for Publishing \& Distribution (Arabic version).

Abdel Munim, A. (1996). Guidance and psychological, social, educational counseling. Gaza: Mansour Press (Arabic version).

Abu Saymeh, S. (1984). Models of academic advising in the credit hour system. Damascus: Arab Center for Research on Higher Education (Arabic version).

Adena D. Young Jones, Tracie D. Burt, Stephanie Dixon \& Melissa J. Hawthorne (2013). Academic advising: does it really impact student success? Quality Assurance in Education, 21(1), 7-19.

Ahmed, N. (2002). Academic advising problems at Yarmouk University as perceived by students. Master Thesis. Irbed: Yarmouk University (Arabic version).

Aldahadha, B. \& Al-Bahrani, M. (2012). Academic advising services among Sultan Qaboos University and University of Nizwa students in light of some variables. International Journal for Research in Education (IJRE), 1(32), 23-44.

Allogmani, G. (2014). Academic advising obstacles in the Islamic University from students view. International Interdisciplinary Journal of Education, 3(2), 103-122.

Al-Quds University (2014). Facts and figures.

Atiyat, A. \& Mufti, F. (1986). Academic advising. Arab organization for admission in Arab countries universities. Irbed: Yarmouk University (Arabic version).

Beatty, J. (1991). The National Academic Advising Association: a brief narrative history. NACADA Journal, 11(1), 5-25.

Bishop, C. (1987). Teaching at Johns Hopkins: the first generation. History of Education, Quarterly, 27(4), 499-523.

Carlin, T. (2000). Academic advising: visit your advisor frequently. http: www.Edindoro.Edu/ewis/acaff/suppserv/tips/cat.htm1.

Chickering, A. \& Gamson, Z. (1987). Seven principles for good practice in undergraduate education. American Association for Higher Education Bulletin, 39(7), 3-7.

Crookston, B. (1972). A developmental view of academic advising as a teaching. Journal of College Student Personnel, 13(2), 12-17. 
Dibia, N. \& Obi, O. (2013). Academic advising and counseling in universities in South East Nigeria: a new perspective. Academic Journal of Interdisciplinary Studies, 2(10), 121-129.

Frost, S. (1991). Academic advising for student success: a system of shared responsibility. ASHE-ERIC Higher Education Research Report no. 3, Washington D.C., School of Education and Human Development, George Washington University.

Grites, T. (1979). Academic advising: getting us through the eighties. AAHE-ERIC Higher Education Research Report no. 7, Washington D. C., American Association for Higher Education.

Habley, W. (1988). Introduction and overview. In W. Habley (Ed.). The status and future of academic advising, problems and promise, lowa: American College testing program.

Hammad, M. (2000). The reality of academic advising in Bethlehem and Al-Quds Universities as perceived by advisors and students. Master Thesis. Jerusalem: Al-Quds University.

Harithy, D. (2000). Impact of electronic academic advising on academic achievement of Faculty of Education students at King Faisal University. Arab Educational Journal, 20(2): 170-190 (Arabic version).

Hunter, M. \& White, E. (2004). Could fixing academic advising fix higher education? About Campus, 9(1), 20-25.

Kelley, B. (2008). Significant learning, significant advising. NACADA Journal, 28(1), 19-28.

Marques, J. (2005). Best practices in adult advising: a team conclusion. Recruitment \& Retention in Higher Education, 19 (8), 4-5.

Melvin, M. (2002). Academic advising: importance of student/advisor relationship. http: www.Edindoro.Edu/ewis/acaff/suppserv/tips/ cat1.tip7.htm1.

Midgen, J. (1989). The professional advisor. NACADA Journal, 9(1), 63-68.

Mohammed, Y. (1995). Students' attitude towards academic advising and its relationship to their academic adjustment. Journal of the E. R. C., 4(8), 93-119.

Muola, JM., Maithya, R. \& Mwinzi, AM (2011).The effect of academic advising on academic performance of university students in Kenyan Universities. African Research Review, 5(5), 332-345.

Najim, S. \& Rashad, A. (1996). Function of academic advising as perceived by students in different academic levels and major. Faculty of Education, King Faisal University (Arabic version).

National Academic Advising Association (NACADA) (2004). NACADA statement of core values of academic advising, available at: www.nacada.ksu.edu/Clearinghouse/Advisinglssues/Core-Values.htm.

O'Banion, T. (1972). An academic advising model. Junior College Journal, 42(6), 62-69.

Oliver, Y. (1978). Credit hour system: its origin and development. Kuwait: Kuwait University (Arabic version).

Omari. K. (1986). Academic advising in the context of the credit hour system. Damascus: Arab Center for Research on Higher Education (Arabic version).

Pargett, K. (2011). The effects of academic advising on college student development in higher education. Master thesis, Lincoln: University of Nebraska.

Petress, K. (2000). How to be a good advisee. Education 120(3), 598-600.

Pietras, S. (2010). The impact of academic advising on GPA and retention at the community college level. PhD. Dissertation, Indiana University of Pennsylvania.

Rabai, A. (1984). Academic advising and registration: problems and solutions. Damascus: Arab Center for Research on Higher Education (Arabic version).

Rudolph, F. (1962). The American college and university: a history. New York, Vintage Books.

Sayyid Ahmed, S. \& Rawi, M. (1995). Academic advising at the UAE University as perceived by staff and students and their suggestions for its development. Future of Arab Education, 1(3), 87-136 (Arabic version).

Shbiyl, S. (2004). Problems of academic advising at Al-Albayt University from the viewpoint of students; faculty members; academic advisers \& Department of Admission. Master Thesis. Amman: Al-Albayt University.

Shikhly, A. (1983). Educational guidance at the university using two systems: Jordanian and Iraqi. Beirut: Arab Institute for Research and Publishing.

Tuttle, K. (2000). Academic advising. New Directions for Higher Education, 1(111), 15-24.

Veysey, L. (1965). The emergence of the American university. Chicago: University of Chicago Press.

Winston, R., Miller, T., Enders, S. \& Grites, T. (1984). Developmental academic advising: addressing students' educational, career and personal needs. San Francisco: Jossey-Bass. 
